\title{
Research on the Relationship between Perceived Organizational Support and Performance of Software Engineer
}

\author{
Fu Haiyan ${ }^{1}, \quad$ Chen Dongmei ${ }^{1}$ \\ Department of Business Northeastern University at Qinhuangdao Qinhuangdao, China \\ fhyqhd@126.com
}

\begin{abstract}
The software industry has been one of the fastest growing high-tech industries in China during recent decades. Software engineers are important production elements in software companies. Managing and bring into play these software engineers' professional skills in software companies can influence the company's performance significantly. Software company's overall operating performance is inextricably interrelated to software engineers' job performance. As a result, it is important for human resources managers in software companies to maximize the software engineers' job performance. In this paper, we focus on the software engineers, study the relationship between perceived organizational support and software engineer's performance, and put forward some effective proposals in order to improve software engineers' job performance.
\end{abstract}

Key words: relationship; perceived organizational support; performance ; software engineer

\section{Introduction}

Software companies' business performance is basically depended on software engineer's personal work performance. Human resource management aims at that by increasing the software engineer's in- dividual job performance, the company can achieve its business goals.

Software engineer is a group of professionals who has special requirements on the working environment and their self-developments. Nowadays, however, lacking of the understanding of work characteristics and self-needs of the software engineer in some of the software enterprises lead to lower perceived organizational support, less enthusiasm of work and insufficient tapping of work potential Thus will affect the working efficiency and quality of the entire development team and ultimately lead to huge economic losses of the enterprise.

\section{Concept and Characteristics of Software Engineers}

\subsection{Concept}

The definition of software engineers has broad sense and narrow sense. Wiki Encyclopedia define the software engineer as " a profession dedicated to designing, implementing, and modifying software so that it is of higher quality, more affordable, maintainable, and faster to build". It is a "systematic approach to the analysis, design, assessment, implementation, test, maintenance and re-engineering of a software by applying engineering to the software" ${ }^{[1]}$.It is a broad concept, including software designers, software architect, software project managers, programmers and others. Professor Zhao Xiping defined the generalized software engineer in 
the studies of the Potential of Competency as" staff in every period of software life cycle, including product managers, system analysts, software engineers, test engineers and maintenance engineers" and the narrow definition is "staff engaged in the software detailed design, coding and unit testing " ${ }^{[2]}$. In this paper, a software engineer is defined by narrow sense.

\subsection{Characteristics}

Software engineers are typical knowledge-based professionals. Most of them have advanced academic degrees and can master professional knowledge skillfully. They are more spontaneous, individual, challenging and innovative. They pay more attention to updating their own skills and knowledge and the communication between team members ${ }^{[3]}$.

\subsubsection{Job Autonomy demand}

After establishing the goal and performance criteria, software engineers can accomplish their work in their own way. The organizations are demanded to provide autonomy in the workplace, working hours and working methods, which enables the engineers to work most effectively.

\subsubsection{Self-development needs}

The software engineers' loyalty and dependency towards knowledge and professional skills are significantly higher than which are to the company. Most of them emphasize on their own development, which is to pursue the improvement of self-knowledge and skills and the realization of self-value.

Software engineers need to learn continually, to communicate and share knowledge with each other to maintain unique capabilities and exclusive skills. The organizations are required to be able to create a good learning environment and provide related technical training so as to meet their need of knowledge update and career development.

\subsubsection{Team cooperation needs}

With the purpose of communication, cooperation and knowledge sharing among team members, software engineers usually work in teams. Therefore, managers of software companies need to provide their engineers with the proper team members who are willing to do teamwork.

\subsubsection{Fairness and justice demand}

How software engineers' payment agrees with their effort matters a lot. Software engineers require companies to give timely, fair, just and reasonable payment, according to their performance and technological achievements. Also, they require companies to evaluate properly on their personal value and contribution.

\section{Proceived Organizational Support and Performance Status of Software Engineer}

\subsection{Proceived Organizational Support Status}

It comes out from the experiences that employees themselves were valued by the organization, which satisfies the emotional demands and will affect the thoughts and actions at work. An employee with high perceived organizational support often shows higher efficiency of work ${ }^{[4]}$.

It is indicated in researches that software engineers who are older, more experienced or in higher positions receive a higher recognition from the company. Those engineers have rich project experience, professional techniques and skills and thus they can make a great contribution to the company. Therefore, they receive a higher recognition from the company. The recognition of software engineers with Master or Doctor's degree are below the average level, indicating that companies should pay more attention to the value of high degree engineers. Better-educated and higher-position software engineers perceive more support and concern for their work and interests from the 
company, indicating that the software companies attach great importance to education and ability in the use of talent. Relatively speaking, companies will give better-educated and more capable software engineers higher work support and more attention to their interests.

\subsection{Performance Status}

Performance refers to the employees in the work process in some way with the organizational goals achieved an activity closely related to results or behaviors. It includes two aspects: one refers to the results of the work, known as the equivalent of performance, such as work efficiency, work efficiency, or profits generated; the other hand refers to the behavior of the resulting work, ability and so on. Results and behavior are mutually reinforcing, the result is the ultimate goal of the work, the act would be able to influence and control goals .

It is shown in surveys that some factors, such as age, working experience and education affect the interpersonal promotion a lot. The older engineers with more experience have higher interpersonal promotion. This is because as the age and working experience increase, the engineers tend to be more concerned and helpful to their team members and at the same time pay more attention to create positive relationships. Meanwhile, the highly educated software engineers often have stronger emotional or intellectual quotient so that they do better in creating positive relationships than the less educated software engineers. The differences in education and working experience are caused by the fact that the better-educated and more experienced have more professional knowledge and skills. As a consequence, they can stand out from the rest of software engineers and are competent at software work.

\subsection{The Relationship of Perceived Or- ganizational Support and Job Per- formance}

As we can see in the results of many studies, the higher the perceived organizational support of software engineers are, the better their task performance, interpersonal promotion and work dedication are. When the software engineers' needs of organizational support are met, they will voluntarily devote themselves to work with higher enthusiasm, initiative, creativity and dedication. They will also create a good atmosphere of interpersonal relationship and team cooperation. Given the proper care and appreciation, software engineers will have the sense of duty and will provide a better job performance in return.

\section{Proposals For Software Company}

\subsection{Increase the Autonomy}

In practical work, by establishing a relaxed working environment and working systems and using the methods and target management to develop a proper working schedule, the managers can create a perfect environment for engineers to independently complete the task within the established organizational goals and selfassessment system.

\subsection{Increase the Participation}

Software engineers should be given certain rights, so that they have the opportunity to participate in company management and development decisionmaking at all levels of research and discussion. Full authority, high involvement and sufficient job autonomy fulfill software engineers' needs of trust and respect and can also enhance their emotional dependence on the company. It is helpful for increasing software engineers' job performance and perceived organizational support. 


\subsection{Concerning about the Career Development}

Being under 35 years old and having great concern about their own career, employees in the software industry require companies to establish a relatively complete system of career development, so that every engineer can have an upside potential. On the other hand, it is necessary for companies to understand the different stages of software engineers' career development needs. According to their needs, companies should provide engineers appropriate technical training and create favorable external conditions to help them achieve their own career development. Practice has proved that once a software engineer's career development has been fulfilled, he will give a more remarkable performance to the organization in return.

\subsection{Emphasis on Potential Value of Highly Educated}

Some highly educated software engineers with great expertise are lack of experience, but as their project experience and capability broadens, they can create more value for the company. For them, when they have made some progress in technology, enterprises should give them appropriate praise and award. When they have come up with some certain innovative ideas, enterprises should give them a positive reply and encourage them to realize their ideas. When they come against some difficulties at work, the enterprise should offer advice and encouragement and rearrange their posts at the appropriate time rather than dismiss them.

\subsection{Establishment of an Effective Communication Mechanism}

First, lower management levels to strengthen direct communication channels. The more levels of management are, the more easily the transfer of information would be distorted. Companies should encourage diagonal communica- tion. Second, encourage to establish a number of internal informal groups that gather engineers who share a common interest in software technique to discuss technical issues. Third, managers can regularly talk with the staff to understand the work of employees and give some practical advice in order to correct the deficiencies in time and increase the usefulness of management.

\section{Conclusion}

In this paper, by researching on the perceived organizational support and performance of the software engineer, we tabled several proposals on improving software engineers' spontaneity and participation, paying more attention on engineers' career development and the potential of the well-educated and build up an efficient communication mechanism, so as to improve the perceived organizational support and performance of the software engineer.

\section{References}

[1] Zhao Xiping, Zhou Mi, Li Jian, Zhao Wenhong, Software engineer competency potential empirical research, Research management, 2007, vol.28 (5), pp.110-114 (In Chinese).

[2] Liu Cong. Organizational support of influence factors and in the organization management application, Economic theory, 2009, vol.12 (24), pp.53-54 (In Chinese).

[3] Michael Riketta, Attitudinal organizational commitment and job performance: a meta-analysis, Journal of organizational behavior, 2002, vol.23, pp. 257-265.

[4] Xia Aihua, A software development company employee incentive mechanism, Shanghai: Shanghai Jiao Tong University, 2009 (In Chinese). 